\title{
Associação à positividade da Lawsonia intracellularis com a expressão clínico-patológica da infecção em suínos da região metropolitana de Bucaramanga (Santander, Colômbia)
}

\author{
[Association to positivity of Lawsonia intracellularis with the clinical and \\ pathologic expression of infection in swine from the metropolitan \\ area of Bucaramanga (Santander, Colombia)] \\ A.P. Jiménez, L.Z. Duarte, L.S. Cortez, M. Granados, C. Florez, \\ A. Villamizar, J.A. Parra-Martin \\ Universidad Cooperativa de Colombia - UCC - Bucaramanga, CO
}

\section{RESUMO}

Porções de íleo terminal foram coletados de 100 suínos com sinais de doença gastrointestinal na área metropolitana de Bucaramanga, a fim de se estudar a eficiência do diagnóstico de enteropatia proliferativa suína (PPE) pela técnica de PCR aninha (PCRa) empregando sequências específicas (primers) para $L$. intracellularis: 16S ARN região (270pb) e sua correlação com achados clínicos e patológicos. Todas as amostras foram processadas para se determinar a associação entre positividade por PCR, os sinais clínicos, os achados de necropsia e as lesões histológicas. Cinquenta e seis por cento das amostras foram positivas para $L$. intracellularis pela PCRa. Só $2 \%$ exibiram resultados positivos pela técnica WarthinStarry. Trinta e um de 100 animais com sinais de anorexia resultaram positivos para PCRa $(\mathrm{P}>0,05)$. Não houve associação $(\mathrm{P}<0,05)$ entre diarreia e queda no crescimento, bem como associação $(\mathrm{P}<0,05)$ entre achados anatomopatológicos e histológicos com PCRa positivas.

Palavras-chave: ileíte suína, PCR, Warthin-Starry

\begin{abstract}
Fragments of terminal ileum were collected from 100 pigs at slaughter from Bucaramanga Metropolitan Area (Santander, Colombia), to study the efficacy of the diagnosis of porcine proliferative enterophaty (PPE) through the technique of nested polymerase chain reaction (PCRa), employing specific sequences (primers) for L. intracellularis: 165 ARN region (270pb) and his correlation with clinic and pathological findings. All samples were processed by standard histological methods and stained with a Warthin-Starry technique. All samples were processed to determinate the association between positive PCRa results, clinical signs and necropsy findings. 56\% of the 100 samples were positive for L. intracellularis through PCRa technic. Only 2\% exhibited positive results through Warthin-Starry technique. A total of 31 (100) animals with anorexic symptoms were associated with positive results from PCRa $(P>, 05)$. No associations $(P<0.05)$ were observed between diarrhea and delayed growth. No associations $(P<0.05)$ were observed between anatomopathological and histological findings with positive PCRa.
\end{abstract}

Keywords: porcine proliferative enterophaty, PCR, Warthin-Starry

\section{INTRODUÇÃO}

A enteropatia proliferativa suína (EPS) é uma doença infecciosa bacteriana que tem origem na bactéria Gram (-) Lawsonia intracellularis, caracterizada pela proliferação de células do

Recebido em 7 de setembro de 2016

Aceito em 25 de novembro de 2016

E-mail: angela.jimenez@campusucc.edu.co epitélio, espessamento da parede do intestino delgado e às vezes na porção superior do cólon. A incidência da infecção pela $L$. intracellularis em suínos tem aumentado no mundo; países como México, Estados Unidos e Espanha reportam positividades de 30-40\% (Escatel et al., 2005). 
O impacto econômico gerado pelos espécimes intestinais do tipo ileíte suíno pode ser de grande relevância em países como Brasil, Chile, Argentina, México e Colômbia, por estes serem os maiores produtores de carne suína na região (Boari et al., 2014; Varela, 2014). Na Colômbia, foram encontradas prevalências de 20-87\%, principalmente nos estados de Antioquia e Cundinamarca (Barbosa et al., 2005).

No estado de Santander, não existe informação que permita ter um panorama atual sobre a situação da infecção na indústria suína. Assim, esta pesquisa teve como objetivo determinar, pela técnica de reação em cadeia da polimerase (PCRa) aninhada, a presença de $L$. intracellularis em suínos da região metropolitana de Bucaramanga, no estado de Santander (Colômbia), e sua associação positiva com os achados clínico-patológicos para o estabelecimento da linha-base, que permitam determinar a situação epidemiológica da $L$. intracellularis.

\section{MATERIAL E MÉTODOS}

De granjas suinocultoras da região metropolitana de Bucaramanga, foram coletadas 100 amostras de porções terminais de íleos de suínos mortos que apresentaram sintomas relacionados com a doença intestinal, tais como anorexia, perda de peso, diarreia e baixa conversão. As variáveis idade e sexo foram desconsideradas. Foram registrados, para cada animal, os sinais clínicos, além dos achados de necropsia (colite, espessamento da parede intestinal, enterite, enterite hemorrágica e enterite necrótica).

$\mathrm{Na}$ amostragem, a porção de íleo foi dividida em duas: a primeira foi armazenada em solução buffer TE 0,1X (Tris HCl 1M; EDTA 0,5M; pH $8,0)$, sendo conservada sob ultracongelamento ($60^{\circ} \mathrm{C}$ ) para extração de ácido desoxirribonucleico (ADN) e PCR; a outra porção foi submersa em formol a 10\%, armazenada e mantida em temperatura ambiente para análise histopatológica.

Para cada uma das 100 amostras, foi extraído ADN cromossomal usando-se kit de extração Purelink Genomic DNA Mini kit Invitrogen $₫$, segundo metodologia descrita por Martínez e Silva (2013).
Terminado o processo de extração, as amostras de ADN foram quantificadas por fluorímetro Qubit Fluorometer ${ }^{\circledR}$ (Invitrogen S.A.). Cada um dos $\mathrm{ADN}$ foi diluído à concentração de $10 \mathrm{ng} \cdot \mu \mathrm{L}^{-}$ ${ }^{1}$ em água estéril e armazenado a $-60^{\circ} \mathrm{C}$. Para constatar a qualidade dos extratos de ADN obtidos, foi feita uma eletroforese em gel de agarose $\left(\right.$ Merck $\left.^{\circledR}\right)$ a $1,5 \%$, por uma hora, a $74 \mathrm{~V}$, utilizando-se um padrão de peso molecular de $100 \mathrm{pb}$ Promega ${ }^{\circledR}$ e corante AZ Visiom Amresco®.

Para cada um dos ADN quantificados e diluídos, foi feita uma PCR aninhada para amplificar o gene 16S ARN de L. intracellularis de 270pb. Realizou-se uma primeira amplificação da porção de 319pb do gene 16S ARN com primers externos: 5'-TAT GGC TGT CAA ACA CTC CG-3' e 5'-TGA AGG TAT TGG TAT TCT CC-3'; o produto dessa primeira amplificação foi usado de molde para uma segunda reação que amplificou uma porção interna de $270 \mathrm{pb}$ do gene 16S RNA de L. intracellularis, utilizando-se os primers internos específicos: 5'-TTA CAG GTG AAG TTA TTG GG-3' e 5'-CTT TCT CAT GTC CCA TAA GC-3 (Jones et al., 1993; Jacobson et al., 2004). As condições das PCRs e a obtenção de controles positivos de microrganismos inteiros da vacina Enterisol ${ }^{\circledR}$ Ileítis (Boheringer Ingelheim) foram padronizadas (Martínez e Silva, 2013).

Para cada reação de PCR, foi incluída como controle negativo água, substituindo o $\mathrm{ADN}$ molde, e mistura de reagentes sem água nem ADN molde.

As condições ótimas para as PCR, tanto para aquelas com primers internos quanto para as outras com primers externos, incluíram: $2,5 \mathrm{~mm}$ de $\mathrm{MgCl}_{2} ; 0,15 \mathrm{MM}$ de cada desoxirribonucleotídeo trifosfato (DNTP); $1 \mathrm{X}$ de buffer de reação; $0,8 \mu \mathrm{m}$ de cada primer; y $2,5 \mathrm{U}$ da enzima ADN Taq polimerase. As temperaturas ótimas de anelamento para a PCR simples e aninhada foram de 50 e $55^{\circ} \mathrm{C}$, respectivamente.

Os produtos de ambas as PCRs foram visualizados por eletroforese em gel de agarose a $1,5 \%$, misturando-se $7 \mu \mathrm{L}$ de amplificado com $3 \mu \mathrm{L}$ de corante EZ-Vision DNA Dye AMRESCO (Solon, OH, EUA), em solução buffer TAE $1 \mathrm{X}$ a $74 \mathrm{~V}$, por uma hora. Empregou- 
se padrão de peso molecular de $100 \mathrm{pb}$ de Promega ${ }^{\circledR}$. Os géis foram visualizados em transiluminador UV (Biotec-fischer ${ }^{\circledR}$ ).

As amostras de íleo foram conservadas em formol a $10 \%$. Foi feita montagem dos tecidos nas lâminas de vidro no Laboratório de Patologia da Universidade Industrial de Santander. Foram então enviadas ao Departamento de Patologia da Universidade de Antioquia para o procedimento de coloração de Warthin-Starry (Warthin e Chronister, 1920) As lâminas foram analisadas em microscópio óptico de luz (Olympus CX21®) na Universidade Cooperativa de o Departamento Colômbia - Bucaramanga. As lâminas foram, então, analisadas em microscópio óptico de luz (Olympus CX21®). Foram registrados os achados histopatológicos relacionados com a infecção (hiperplasia de células das criptas intestinais, atrofia das vilosidades), assim como a presença do microrganismo.
A análise dos dados incluiu sua descrição (\%) no intuito de determinar as associações entre a positividade por PCR, os sinais clínicos (anorexia, diarreia e déficit de crescimento) e os achados de necropsia (colite, espessamento da parede intestinal, enterite, enterite hemorrágica e enterite necrótica). Utilizou-se o teste quiquadrado para ver o ajuste dos dados. Os resultados de PCR foram comparados com os dados de histopatologia por meio do teste de Fisher.

\section{RESULTADOS}

De todas as 100 amostras de tecido, foi obtido ADN cromossomal de enterócitos (Fig. 1). As concentrações foram desde $20 \mu \mathrm{g} \cdot \mathrm{mL}^{-1}$ até $800 \mu \mathrm{g} \cdot \mathrm{mL}^{-1}$.

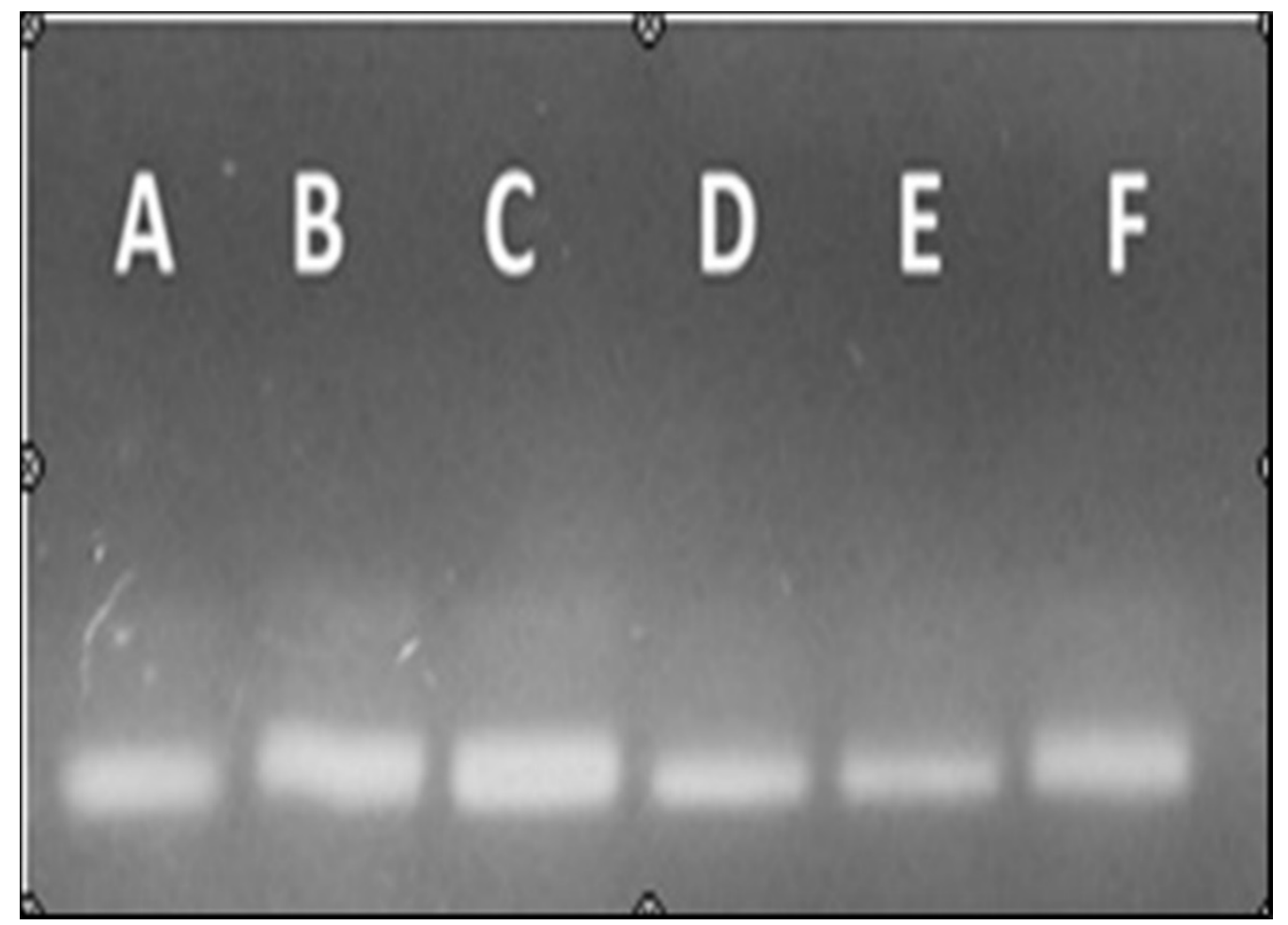

Figura 1. Eletroforese em gel de agarose 1,5\%. A-F: ADN cromossomal extraído de íleo suíno (Purelink Genomic DNA Mini kit Invitrogen () ).

Cinquenta e seis por cento das amostras avaliadas pela PCR aninhada resultaram positivas para L. intracellularis. A Fig. 2 apresenta as bandas obtidas nas amostras correspondentes à amplificação da porção de $270 \mathrm{pb}$ do gene ácido ribonucleico ribossômico (ARNr), bandas que coincidem com o controle positivo (ADN obtido de microrganismos 
inteiros purificados: vacina Enterisol $^{\circledR}$ Ileítis (Boheringer Ingelheim). Para cada uma das positivos quanto os negativos comportaram-se reações de PCR realizadas, tanto os controles

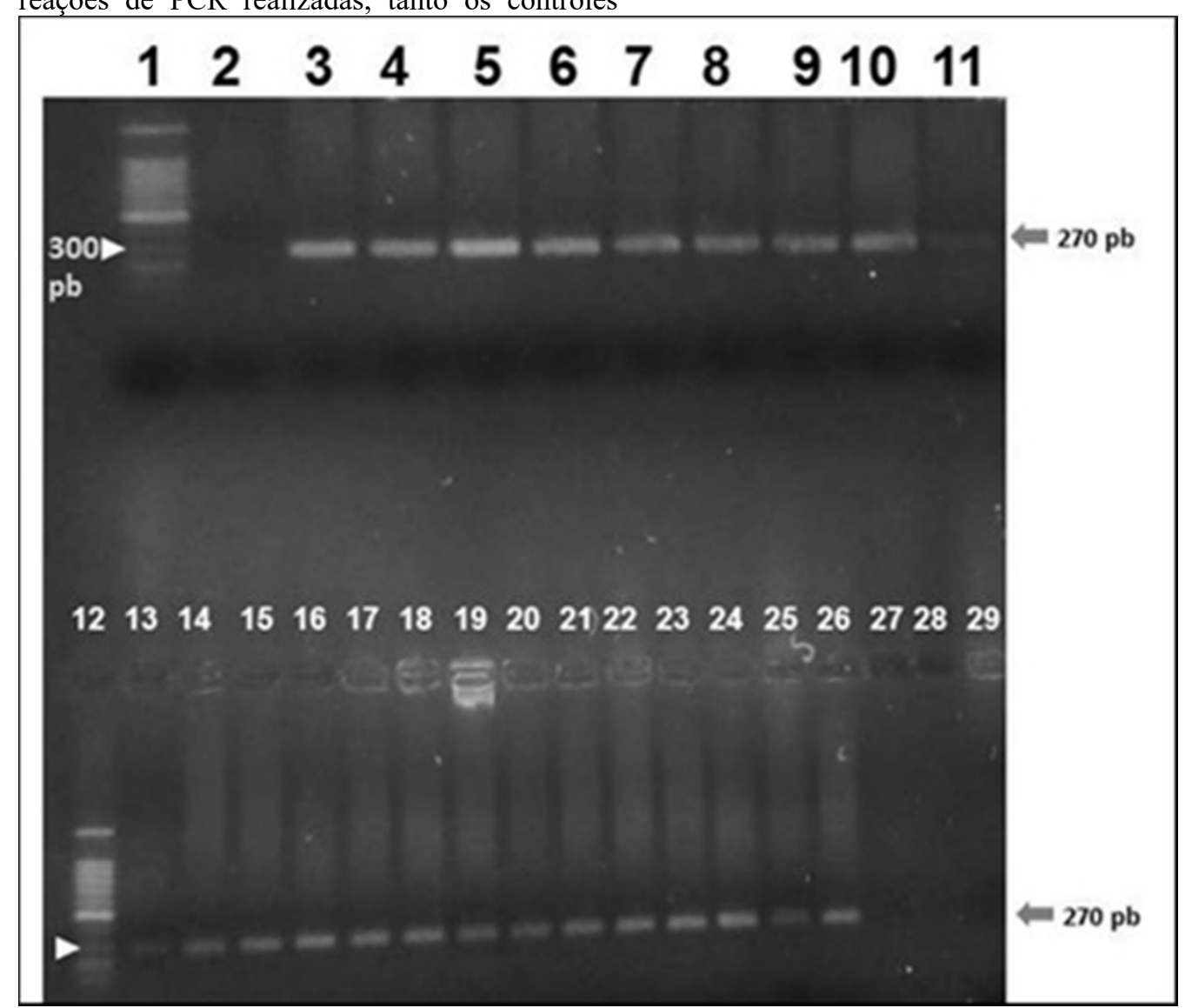

Figura 2. Eletroforese em gel de agarose 1,5\%. Produtos da amplificação da porção de 270pb do gene 16S ARNr de Lawsonia intracellularis. 1 e 12: padrão de peso molecular de 100pb Promega ${ }^{2} ; 2$ e 13: controle positivo; 3 - 26: amostras positivas; 27-29: controle negativos.

Em 2\% dos tecidos analisados com corante de Warthin-Starry, detectou-se hiperplasia leve das criptas intestinais, sem a presença da bactéria. $\mathrm{Na}$ mucosidade intestinal, identificou-se atrofia severa de vilosidades com descamação difusa de enterócitos. O percentual de tecidos que não apresentou hiperplasia de criptas intestinais foi de $2 \%$. Detectou-se a presença da bactéria com morfologia espiral, invadindo a porção apical citoplasmática em enterócitos da cripta intestinal (Fig. 3.). Só duas amostras resultaram positivas por PCR, além de sê-lo também por corante.

Os animais apresentaram anorexia em 31\% dos casos, sendo 23 positivos por PCR, havendo, então, uma associação significativa $(\mathrm{P}<0,05)$ entre a apresentação de anorexia e a positividade por PCR. Não houve associação significativa $(\mathrm{P}>0,05)$ ao serem comparados os resultados de PCR aninhada com apresentação de diarreia ou retardamento no crescimento nem entre os achados anatomopatológicos da necropsia (colite, espessamento da parede intestinal, enterite, enterite hemorrágica e enterite necrótica) e a positividade por PCR.

Os achados histológicos como hiperplasia de criptas intestinais e atrofia de vilosidades não apresentaram associação significativa $(\mathrm{P}>0,05)$ com a positividade por PCR. Ao ser feita a análise estatística dos resultados pelo teste de Fisher, encontrou-se que não há associação entre a positividade por corante Warthin-Starry e a positividade por PCR aninhada. 


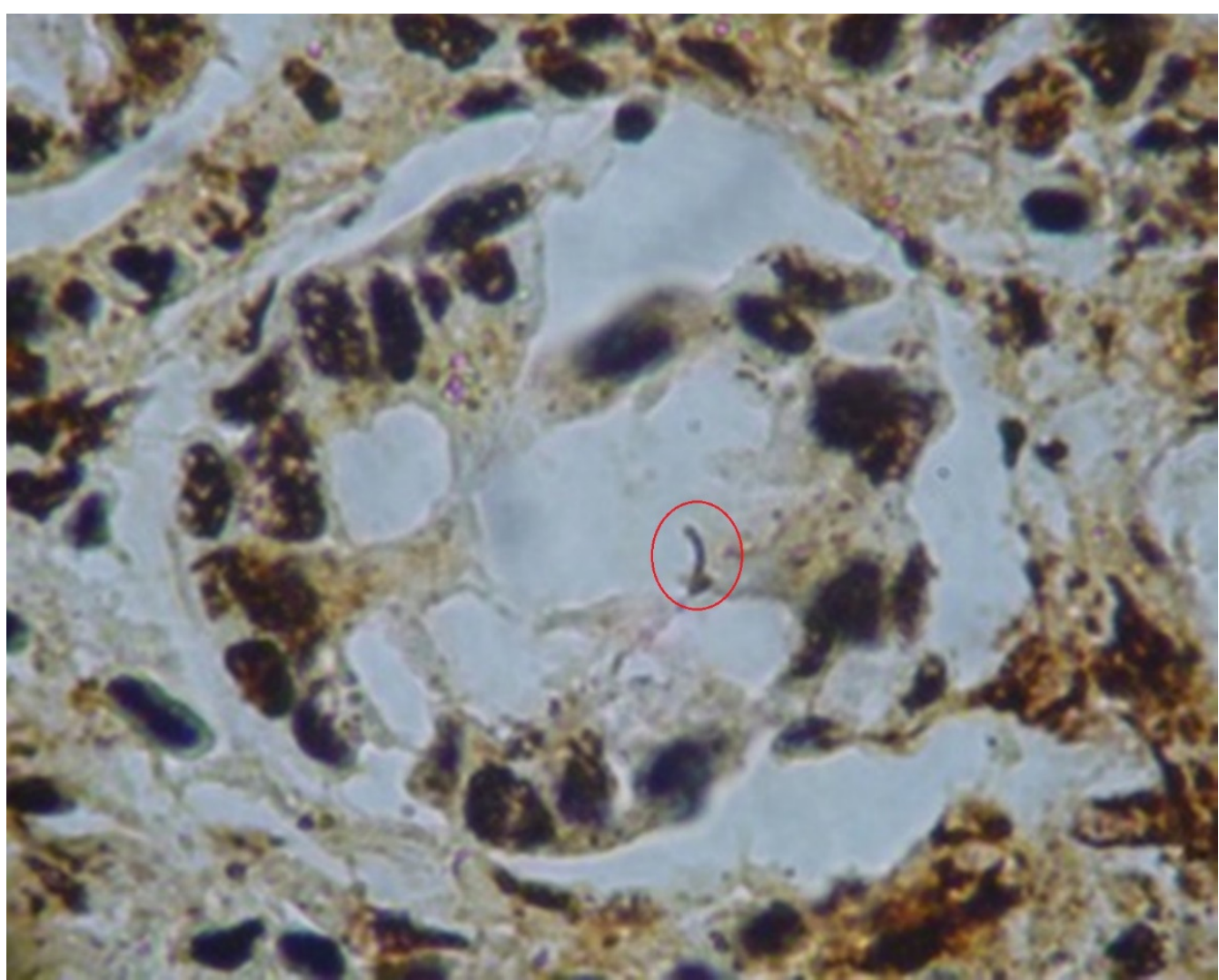

Figura 3. Microfotografia do tecido intestinal suíno (cripta). Histopatologia pela técnica de coloração de Warthin-Starry. Observa-se presença de Lawsonia intracellularis no citoplasma. 100x.

\section{DISCUSSÃO}

O presente estudo confirmou a presença de $L$. intracellularis em granjas suinocultoras da região metropolitana de Bucaramanga, por meio da técnica de PCR aninhada e histopatologia por corante Warthin-Starry. Cinquenta e seis por cento dos animais foram positivos para infecção por PCR. Só $2 \%$ resultaram positivos por corante Warthin-Starry. Achados de Plawinska et al. (2004) foram concordantes: esses autores empregaram PCR aninhada e detectaram ADN de L. intracellularis em 53,3\% (194/364) dos casos estudados.

Na Colômbia, a EPS tem sido diagnosticada com base nas lesões reportadas em necropsia e no diagnóstico histológico, embora se observado ao microscópio com corante Warthin-Starry permite observar a bactéria, o mesmo não é específico para $L$. intracellularis devido ao fato de outros microrganismos morfologicamente similares existirem e de haver limitações quando se aplica a amostras necróticas ou autolisadas. Por isso, em animais em fase necrótica da doença, o diagnóstico por histopatologia para identificação do agente é complexo, pois as lesões necróticas severas em vilosidades intestinais dificultam a detecção da bactéria, sendo, então, de grande relevância as técnicas moleculares, como a PCR, para identificação do agente em fases necróticas da doença. Esse fato é corroborado nesta pesquisa, já que só $2 \%$ dos casos resultaram positivos por corante, sendo, em um dos casos, a estrutura bacteriana difusa em razão das mudanças morfológicas pela necrose ocasionada pelo curso da doença.

O único sinal clínico que apresentou associação significativa com a positividade por PCR foi anorexia; outros autores reportam percentuais baixos $(8 \%)$ de animais com sinais como diarreia e perda da condição corporal (Calle et al., 2006)

Nenhum dos achados de necropsia foi associado significativamente à positividade por PCR, o que poderia estar relacionado com a observação de bactérias extracelulares 
(cocobacilares) nos tecidos avaliados com características morfológicas diferentes de $L$. intracellularis, as quais poderiam estar relacionadas com as lesões encontradas, mas sem ser consequência da $L$. intracellularis, fato que também foi reportado por Rodríguez et al. (2009).

Os resultados histológicos deste estudo são similares aos achados do Barbosa et al. (2005), autores que, baseados num estudo retrospectivo (1998-2004) dos casos diagnosticados pelo Instituto Colombiano Agropecuario (ICA), reportaram que só $11 \%$ dos casos estudados com corante Warthin-Starry apresentaram hiperplasia leve das células epiteliais com diminuição das células caliciformes. Os autores no detectaram a presença da bactéria nos tecidos.

A L. intracellularis tem sido estudada em alguns estados da Colômbia (Rodríguez et al., 2004; Barbosa et al., 2005) empregando-se o método do corante de Warthin-Starry ou a imunohistoquímica para detecção da bactéria, sendo Antioquia, Cundinamarca e Valle del Cauca os estados que apresentam maior número de casos da doença. Muitos outros estados, entretanto, não têm sido estudados, sendo, então, esta pesquisa o primeiro reporte de detecção molecular da bactéria $L$. intracellularis em granjas suinocultoras do estado de Santander, o que representa o primeiro elo para determinar a situação epidemiológica da doença e o desenvolvimento de programas de prevenção e controle pelo estado.

\section{REFERÊNCIAS}

BARBOSA, A.; GIL, A.; RUIZ, S.; RINCÓN, M. et al. Detección de Lawsonia intracellularis en cerdos por medio de las técnicas de tinción de plata e imnunohistoquímica. Rev. Med. Vet. Zootec., v.52, p.12-23, 2005 .

BOARI, R.; CHUARD, N.; FERNÁNDEZ, V.; POUILLER, P. Mercado de ganados y carnes proyecciones 2023 OCDE-FAO, 2014. Disponible en : $<$ http://www.agroindustria.gob.ar/site/ganaderia/bovin os $/ 05=$ Mercados $/ 04=$ Carnes/ archivos $/ 000003=$ Merca do\%20internacional $\% 20 \mathrm{de} \% 20$ carnes/000001-

Proyecci\%C3\%B3n\%20OCDE\%20FAO\%20carnes\% 202014-2023.pdf>. Consultado en: 10 fev. 2016.
CALLE, S.; CHAVERA, A.; SANDOVAL, N. et al. Detección de ileitis necrótica causada por Lawsonia intracellularis en porcinos de granjas tecnificadas de la zona de Lima. Rev. Inv. Vet., v.17, p.67-72, 2006.

ESCATEL, G.S.; VARGAS, F.D.; CARRERA, E. et al. Determinación de la frecuencia de piaras infectadas con Lawsonia intracellularis en México mediante la técnica de PCR. Тес. Реси. Мex., v.2, p.211-218, 2005.

JACOBSON, M.; ASPAN, A.; KÖNIGSSON, M.H. et al. Routine diagnostics of Lawsonia intracellularis performed by PCR, serological and post mortem examination, with special emphasis on sample preparation methods for PCR. Vet. Microbiol., v.102, p.189-201, 2004.

JONES, G.F.; WARD, G.E.; MURTAUGH, M.P. et al. Enhanced detection of intracellular organism of swine proliferative enteritis, ileal symbiont intracellularis, in feces by polymerase chain reaction. J. Clin. Microbiol., v.31, p.2611-2615, 1993.

MARTINEZ, M.; SILVA, Y. Estandarización de una PCR anidada para la detección de Lawsonia intracellularis en tejidos porcinos (Fase I proyecto CONADI: prevalencia de Lawsonia intracellularis en explotaciones porcinas de la zona metropolitana de Bucaramanga), 2013. Monografia (Projeto de graduação) - Escola de Medicina Veterinaria y Zootecnia, Universidad Cooperativa de Colombia, Bucaramanga, Col.

PLAWINSKA, J.; JAKUBOWSKI, T.; RZEWUSKA, M.; BINEK, M. Occurrence of Lawsonia intracellularis and Brachyspira spp. infection in swine suffering from diarrhoea. In: CONGRESS PROCEEDINGS OF THE Internaional Pig Veterinary Society, 18., 2004, Hamburg. Proceedings... Hamburg: [s.n.], 2004. p.287.

RODRÍGUEZ, B.; ARANZAZU, D.; GIRALDO, G. et al. Prevalencia de enteropatía proliferativa porcina y caracterización histopatológica de las lesiones asociadas en cerdos sacrificados en el Matadero Municipal de Medellín., Rev. Col. Cienc. Pecu., v.17, p.11-19, 2009.

VARELA, D.B. Producción de carne en America Latina. PORCIAMERICAS CONGRESO NACIONAL, ASOCIACIÓN COLOMBIANA DE PORCICULTORES, 17., 2014. Disponíble en: $<$ http://www.porcicol.org.co/porcicultores/images/pru eba2/3DIEGOBranaProdCarneLAPorciamericas2014. pdf $>$. Consultado en: 18 fev. 2016.

WARTHIN, A.; CHRONISTER, A. A more rapid and improved method of demonstrating spirochetes in tissues (Warthin and Starry's cover-glass method). Am. J. Syphilis, v.4, p.97-103, 1920. 